\author{
John Chelliah (Corresponding Author) \\ School of Management \\ University of Technology, Sydney \\ Samantha Georges \\ School of Management \\ University of Technology, Sydney
}

\title{
Consulting firm identity: the online effort to differentiate and compete
}

\section{Introduction}

The nature of the consulting industry necessitates an organizational commitment to identity production and management to ensure the organization is knowable and has a chance at longevity. The ability for organizations to differentiate themselves is an important factor in their survival (Clark and Salaman, 1998). The attempt on the part of consulting firms to differentiate from one another is made more difficult by the saturated presence of these firms online. Consequently, the ability to separate one consulting organization from another in a virtual space relies on something intangible: the identity consultancies portray through the stories on their websites. In this interconnected world, simple web searches allow end-users (the client) the ability to research an organization before any contact has been made. The identity an organization's website portrays then becomes an important factor in signaling to and enticing prospective client interest. It is this phenomenon that this paper seeks to explore. The main purpose of this research is to examine the official identity consulting organizations use in describing their work. In so doing, the study endeavors to highlight how consulting firms try to differentiate themselves in an industry that is both highly competitive and frequently changing.

\section{Organizational Identity}

By asking the question "Who are we as an organization?" members of the organization are able to identify a shared belief, something that is observed through organizational experiences as a definable component of the organization. It is an organization's central, enduring and distinctive characteristic that differentiates it from another (Whetten, 2006). Organizational identity can be conceptualized as a set of rules and social cues that specify elements the organization is likely to possess; it might also be attributes of culture, core values and practices that encompass the collective understanding of an organization.

\section{Consultant Identity}

In the context of consulting work, there has been significant work on the identity of consultants. This is still somewhat ambiguous, as the core definitional points of what constitute functions of identity are not agreed upon. This research paper draws together three key typologies of identity drawn from literature.

The identity of the expert can be broken down into three levels. At the top are the management stars, the gurus of the field (Clark \& Salaman, 1996; Alvesson \& Robertson, 2006; Fincham \& Clark, 2002). In the middle are customized thinkers of 
the field, not at the calibre of the guru, but individuals who still have specialized knowledge (Maister 2004). At the bottom are the experts who specialize in particular methodologies, who, although offering a somewhat standardized technique, can still offer customized solutions (Barber \& Nord 1977; Nees \& Grenier 1985). Each level is characterized by different functions, from the gurus that transform the organization, the thinkers diagnosing and customizing organizational problems and finally the assurance of a proven technique that can be applied to a problem. Excluding the identity of the guru, as the title is more typically assigned to an individual than a firm (the focus of the research), the second and third levels of the consultant become the basis of two of the conceptualized identities. The first being the Thinker, characterized by its customized solutions and the second, the Researcher.

The level of interaction the consultant has with the clients becomes an important variable in itself, with many of the theorists using the variable as a defining characteristic of the consultant. A highly collaborative identity may be identified in almost all the theorists' conceptions of the consultant. For example, Maister (2004) uses interaction as one of two dependent variables that intersect to create a type of consulting identity. Acknowledging the significant presence of the consultant as a collaborative partner, the third and final conceptualised identity is created through the Confidant.

Whether the consultant provides a customized or standardized service also becomes an important differentiator; it is in this differentiation that the difference between the Thinker and the Researcher is exemplified. The creativity and innovation of the Thinker is separated from the consultant who specializes in a specific technique, be that a type of methodology or the approach employed by the Researcher (Barber \& Nord 1977). Another differentiator comes in the form of established rituals of consultants that provide the client with a sense of security in trusting a method that has been proven to bring results, a service provided by the Researcher (Schuyt \& Schuijt 1998). Maister (2004) argues that many of the large consulting organizations do successfully employ established methodologies; this may be specifically seen with McKinsey and Company's highly regarded 7S methodology and Boston Consulting Group's (BCG) matrix. An identity that employs standardized methodologies is that of the Researcher (Steele 1975). The Researcher embodies the objective consultant, mainly trading in data and fact-finding. As a result of the nature of the Researcher, the identity is typically correlated with high-leverage firms, where upper management leverages associates to do standardized research work (Kitay \& Wright 2003).

Table 1 presents taxonomy of the main identities from the literature.

\section{Table 1: Taxonomy of Identities of Consultants}

\section{Insert Table 1}

\section{Online Identity Narrative}

Websites are growing in recognition as a rich data source for the discovery of new phenomena in organizational identity. Sillince and Brown (2009) assert that webbased accounts constitute one genre of collective identity that are particularly interesting because they are sanctioned by senior managers (i.e. are 'official'), and designed for both internal and external consumption. It is through the "official" 
identity claims that an indication of the identity of an organization has or at least seeks to embody can be sensed. An organization's website offers the ability to identify consulting roles because a website is recognized as a social electronic representation on behalf of, or in the name of, members of a community. The constructed persona, even in a virtual space can and is argued to be a representation of material and social factors the organization actually embodies.

While websites have been used as a source of study in examining identity construction in an organizational context, the efficacy of website construction in creating organizational identity for management consultants has not yet been a subject of study.

\section{The research}

Our core research question reads "How do management consulting organizations present themselves through their websites?" In answering the core research question, the study also endeavors to answer a subsidiary question of "What character does the consulting organization personify through their website?" By examining consulting organizations' websites, a picture emerges of their intended identities that they wish to portray.

50 consulting firms operating in Australia were sampled: 27 were International firms and 23 Australian firms. Firms specializing in strategy account for 76\% (38), IT Firms $16 \%$ (8) and the remaining $8 \%$ (4) specialize in HR. Table 2 provides a summary of the consulting firms sampled, each categorized by geographic origin and firm specialization.

Table 2: Breakdown of the sample by geographic origin and specialization

\section{Insert Table 2}

Identity extracts of the 50 firms were sourced from the websites. With a total of 787 extracts analyzed, an average of 16 extracts were coded per organization. Depending on how the organization chose to present information on their websites, an extract constituted of 2 paragraphs to 21 pages. In order to minimize issues of temporal change, all the data was collected on the same day. Once identified, each extract was captured into NVIVO (a qualitative data analysis computer software program) and coded in line with the conceptual framework. A content analysis approach was deployed to analyze the collected data. Content analysis identifies and categorizes patterns read through texts, a vital tool when examining the identity that management consultant firms portray through the multiple stories they publish.

\section{Claims}

Results of our data analysis revealed the following. 
- Researcher. The Researcher, characterized by a clinical approach and a data focus is the most common claim made by the majority (46 or 92\%) of the consulting firms sampled. Ernst and Young, Hay Group and Oceanica present the single identity of the Researcher.

- Thinker and Confidant. Three Australian (Nous Group, Pacific Strategy Partners and FastTrack) and one International firm (Birchman) that all specialize in strategy, did not claim to embody any characteristic of the Researcher. Two firms (Birchman, Nous Group and Pacific Strategy Partners) in claiming to be leaders in the industry, portray an identity of innovation, transformation and partnership, which consequently characterizes their identities as the Thinker and the Confidant. The Thinker is the direct opposite of the Researcher.

- Teacher and Confidant. FastTrack on the other hand does not claim to embody the Thinker but instead the Teacher and the Confidant, focusing on training the client.

- Confidant. The Confidant, whose identity is defined as trustworthy, honest and one who makes realistic recommendations, was the second most frequently claimed identity ( 44 or $88 \%$ ). The majority of the firms that portray this identity typically claim to be a collaborative partner of their clients. Only 6 firms (50/50 split between Australian and International). Within this subset, the firms that do not claim to embody the Confidant include 5 strategy firms and 1 HR firm.

- Researcher, Teacher and the Thinker. Inspiritive, Aon and CompliSpace claim to embody different variations of the Researcher, Teacher and the Thinker.

- Thinker. Comparatively less frequently identified than the other consultant identities, the Thinker is characterized by the characteristics of leadership in the field, innovation and creativity. The Thinker in the literature is theorized to represent the higher order presence in the industry. 66\% (33 firms) of the sample claimed to have at least one element of the Thinker. Innovation was the most frequently claimed characteristic followed by the ability to provide objective and independent perspective.

- Teacher. The identity of the Teacher, something that exists outside the identities framework initially devised, was claimed by 42\% (21 firms). The Teacher might be identified as a consultant identity who primarily relies on workshops and seminars in imparting knowledge and facilitating group learning. Some organizations are more explicit in regards to their identity as the Teacher who imparts knowledge. GerrardBown, an Australian strategy firm, describe how they work in partnership with clients to ensure outcomes benefit from the appropriate blend of GerrardBown's expertise and the clients' knowledge. They believe that this partnership facilitates knowledge transfer and capacity building. It is the identification of knowledge transfer that allows GerrardBown to be confidently aligned with the Teacher. 


\section{Reality of identities in cyberspace}

In examining the claims made on consulting firms' cyberspace, the preliminary answers to the main and subsidiary questions of the research have been identified. The analysis provides an overview on how consulting firms portray themselves through their websites, exploring single, complementary, contradictory and multiple identities used as forms of signals to attract clients. Organizational identity is shaped by rival theories with a focus on whether identity is framed as single or multiple. In studying consulting firms' official identity claims, the sample shows elements of both "forms" of identity.

An overwhelming 94\% of the sample aligns with the theory arguing identity as multiple, ambiguous and contradictory. Going against this trend, 3 firms (Hay Group, Oceanica and Ernst and Young) present themselves as outliers in the data by claiming a single identity i.e. the Researcher. This distinctive posturing in a highly competitive industry may have its merits. For example, for the client who knows what type of work they want done to solve their problem, the Researcher offers the experience and practice of established methodologies. The presentation of a single identity reduces the possibility for confusion by the outsider and more specifically by the hiring client. However, whether the identity reflects the 'real' approach of the organization is another issue. The Researcher for all intents and purposes is an expert, albeit a detached and clinical expert. The claim of a single identity may or may not work in favor of the 3 organizations.

As pointed out previously, an organization's central, enduring and distinctive characteristic based on a set of categorical identity claims differentiates it from another and strengthens the organization's knowable identity. However, this research shows only a small percentage claimed to have a single, distinctive identity. The majority of identities claimed by the consulting firms are thus more appropriately conceived as multiple. With $94 \%$ of consulting organizations claiming a level of multiplicity, the notion of consistency is not supported; the consulting firms in question however are not less successful. Alternately, consistency when applied through the lens of multiple identities does have a place in analyzing complementary identities. 3 consulting firms do claim complementary identities (These are Thinker/Confidant and Teacher/Confidant).

In acknowledging that the majority of consulting firms present multiple identities, it can be argued that a firm does not necessarily need a clear conception of what it stands for or what it wants to be to promote an identity. Multiplicity is exemplified in the identification of the 'Jack of all trades' identity. This could be seen as a byproduct of the consulting industry itself. The consulting industry is masterful at making ambiguous statements often claiming many things and nothing at all; a consequence of what is an intangible service. In claiming to embody multiple identities, consulting firms may be endeavoring to project the image of being able to provide an extensive range of services to the client, justifying their endeavor to be hired. Alternately, the presence of multiple identities may align more with reader's 
everyday experiences which may be more credible than a bland, self-justifying or seemingly 'official text'. Thus, the projection of multiple identities produces a more life-like identity, one that is not simple and clearly constructed but rather diverse and contradictory.

Conversely, the consulting industry can be viewed as a project based industry. That is, the skills and approach the consultant employs would differ for every project undertaken. Claims of multiple identities may then be a manifestation of the projectbased work that dictates consulting work. Ergo, the claim to embody the 'Jack of all trades' may not be an impression management ploy but rather a reflection of possible different identities the consultant within the firm may take on to get the necessary results for the client. Additionally, the Teacher's use of workshops, seminars and emphasis on learning and facilitation warrants a separate taxonomical categorization.

In identifying the Teacher as an identity and not merely a role the consultant fills, a remodelled taxonomy of identities warrants construction as shown in Table 3 below. All the remodelled taxonomy offers a mutually exclusive identity, allowing each to be a definable construct that can be applied when examining data.

\section{Table 3: Remodelled Taxonomy of Consultant Identities}

\section{Insert Table 3}

\section{Conclusion}

Through empirical research on how consulting identities are presented in cyber space, this study offers a contemporary taxonomy of consulting identities and thereby enriches the body of knowledge. The research commenced by synthesising the theories of organizational identity and consulting typologies, reconciling both theory and practice to develop a taxonomical framework. The main contribution of the taxonomy lies in the four consulting characters it identifies. Created from the collective identities sourced through the literature, the characters are theoretically informed and empirically tested. The independent variables of the framework are the most important inputs in the identity formation of the consultant, which is guided by the elements of other theorists' presentation of consultant identities, ensuring a level of reliability is found within the framework.

The study provides an understanding of what the sometimes vague statements on consulting websites actually portray about the organization. Additionally, by not judging the worth of certain typologies, the classification of identities does not favour the consultant or the client, as identity was categorized and not judged to be positive or negative. Instead, it acknowledges the characteristics, the claims consulting websites make, and links them with a theoretically supported character. Translating the study of consulting identities into a virtual space also focuses on what the consulting firm promotes as their 'official' identity. There is no question that the stories published on an organization's website is approved and indeed manipulated by upper management to present a desired identity, be it supported by the consulting service or not. This research identifies that this manipulated image does not form a single cohesive identity but rather an identity that is multiple and ambiguous. Thus, 
the research challenges the idea that consultancy organisations with multiple identities are not as marketable or strong as those with a singular, straightforward construction of identity. Ultimately, this research aims to provide a classification tool that separates 'look-alike consultants' in the virtual paradigm, a tool that can be used by both the client and the consultant. 


\section{References}

Alvesson, M \& Robertson, M. 2006. The best and the brightest: the construction, significance and effects of elite identities in consulting firms. Organization, 13(2) 195-224.

Barber, W. H. \& Nord, W. 1977. Transactions between consultants and clients: a taxonomy. Group and Organization Studies, 2(2), 198-215.

Clark, T. \& Salaman, G. 1996. The management guru as organizational witchdoctor. Organization, 3(1), 85-107.

Clark, T. \& Salaman, G. 1998. Creating the 'right' impression: towards a dramaturgy of management consultancy. Service Industries Journal, 18(1), 18-30.

Fincham, R. \& Clark, T. 2002. 'Introduction: the emergence of critical perspectives on consulting', in T Clark and R Fincham (eds), Critical consulting: new perspectives on the management advice industry, Blackwell Publishers, Oxford.

Kitay, J. \& Wright, C. 2003. Expertise and organizational boundaries: the varying roles of Australian management consultants. Asia Pacific Business Review, 9(3), 21-40.

Maister, D. H. 2004. The anatomy of a consulting firm. in CJ Fombrun \& MD Nevins (eds), The advice business: essential tools and models for management consulting, Pearson Prentice Hall, Upper Saddle River, NJ.

Nees, D. B. \& Greiner, L. E. 1985. Seeing behind the look-like management consultants. Organization Dynamics, Winter, 68-79.

Schuyt, T. N. M. \& Schuijt J. J. M. 1998. Rituals and rules: about magic in consultancy. Journal

Sillince, J. A. A. \& Brown, A. D. 2009. Multiple organizational identities and legitimacy: the rhetoric of police websites. Human Relations, 62,1829-1856.

Steele, F. 1975. Consulting for organizational change. University of Massachusetts Press, Amherst.

Whetten, D. A. 2006. Albert and Whetten revisited: strengthening the concept of organizational identity. Journal of Management Inquiry, 15, 219-234. 